\title{
Does Interpersonal Trust Influence Organizational Behavior?
}

\author{
Aziz BAKAY*
}

\begin{abstract}
This research investigates into interpersonal trust and workplace outcomes in organizations within social exchange perspective. Current study is building upon the theoretical underpinnings of trust studies that pose trust as a psychological state and a social glue. Current research develops a theoretical model of interpersonal trust presuming that different trust objects -namely peers and senior managementhave unique and direct effects on global workplace outcomes: Affective commitment, turnover intention, and job satisfaction. The data was collected via convenience sampling and data consists of 134 professionals working in Turkey. Structural Equation Modeling (SEM) using Partial Least Squares (PLS) is employed to test our model. Findings suggest that trust in peers and trust in senior management translate into higher affective commitment. Results indicate a positive association between job satisfaction and trust in senior management. Turnover intention however, did not significantly associate with any of the trust variables suggesting the difference between economic exchange and social exchange, which involves reciprocal behaviors. Simultaneous investigation of two trust objects in organizations as well as inclusion of variety of contextual factors bring rigor to the scope of the research and the explanations of workplace outcomes.
\end{abstract}

Keywords: Interpersonal Trust, Organizational Behavior, Affective Commitment, Job Satisfaction, Turnover Intention, PLS based SEM

JEL Code Classification: D23, J29, L20, M12

UDC: 005.32

* Assistant Professor of Management, Gediz University, Turkey. E-mail: aziz.bakay@gediz.edu.tr 


\section{Introduction}

With the increasing diversity and uncertainty in the workplace environment, individuals have goals that require interactive behavior with other organizational members including cooperation, reliance and dependence (Mayer, Davis, \&Schoorman, 1995). Assuming the dynamism and change as the elements of the uncertainty that is the "inherent state of nature" (Clampitt, Williams \& Korenak, 2000: 3), trust has been considered to be an essential precondition of stable social relations within social exchange context (Cropanzano \& Mitchell, 2005; Blau, 1964). It is argued that the achievement of organizational goals is predicated on the interpersonal trust among organizational members (McAllister, 1995). Interpersonal trust as an integral and prime element of organizational behavior allows employees to engage efficiently resulting in individual and organizational effectiveness. Managerial practices in mutual exchanges as interdependence of organizational components can be managed and channeled to efficient outcomes if there are confidence and trust in interpersonal relations. Therefore, due to the importance of extensive mutual accommodation as well as social/economic exchange among professionals in today's organizations, it is essential to explore trust, trustworthiness, reliance, and confidence issues with respect to organizational and individual outcomes. Specifically, current research is an attempt to answer the following question: What are the relationships between interpersonal trust and particular organizational behavior?

Meaning of interpersonal trust varies among researchers. The approach towards trust can be argued to be three-fold (Fu, 2004): Individual level, entity level or a 'collective attribute', and community level. Former approach taps upon the characteristics and personality issues whereas the second primarily focuses on success of the institutional deliverables (Misztal, 1996). Putnam (1993) positioned and elaborated on the role of trust within a system of society. Thus, it implies facilitating function of trust in the context of the third approach. Besides, many research studied trust as a component of larger phenomenon; that is social capital (Dasgupta, 2000). The perspective employed in this study is more grounded in the first approach at the individual level, connecting to the risk of losing particular value for the trustor as well as touching upon the other two. Considering the probability of loss upon the results of the interaction of parties, the vulnerability appears to be a right angle to understand trust. The following definition of trust from the literature is embraced throughout this study: "willingness of a party to be vulnerable to the actions of another party based on the expectation that the other will perform a particular action important to the trustor, irrespective of the ability to monitor or control that other party" (Mayer et al., 1995: 712). Based on aforementioned conceptualization of trust, we argue that particular psychological state that individuals experience during work has implications and relate to certain observable behavioral outcomes. 
We attempt to explore the explanatory power of interpersonal trust constructs with respect to globally acknowledged organizational behavior. Trust in peers and trust in senior management are hypothesized to have simultaneous and distinctive influence on the level of organizational commitment, and the extent to which the individual experiences satisfaction with the job in general, and the level of turnover intention. Even though there are studies exploring the impact of interpersonal trust on particular organizational behavior (e.g. Yang, 2005; Dirks \&Ferrin, 2002), current study develops a conceptual model involving contextual factors that aim to capture the social psychology of the work environment. This study employs a normative point of view on interpersonal trust implying positive and direct effects on workplace and behavioral outcomes. Thus, this study aims to contribute to the limited empirical literature through the test of a conceptual trust model that involves multiple interpersonal trust foci as well as contextual factors.

\section{Literature Review}

Interpersonal trust as a psychological state is argued to be associated with particular organizational behavior (e.g., Mayer et al., 1995; Rich, 1997; Yang, 2005). As such, commitment to an organization implies a special connection that has several facets between the individual and the entity as a whole (Meyer \& Allen, 1997). It is arguable that considering the social psychological environment of the workplace, individuals can identify organizational members as the entity itself. Especially the attitudinal experiences of the individuals towards the top management of the organization are supposedly highly correlated with the experiences of the individual in regards to the entity as a whole. Therefore, it is important to highlight the experiences of an organizational member towards his/her peers as well as senior management to understand the connection between individual self and the organization as a whole which in fact heavily characterize organizational commitment. At this point, the definition of multidimensional organizational commitment (Meyer \& Allen, 1991) is beneficial for theorizing the aforementioned link:

Affective commitment refers to the employee's emotional attachment to, identification with, and involvement in the organization. Employees with a strong affective commitment continue employment with the organization because they want to do so. Continuance commitment refers to an awareness of the costs associated with leaving the organization... [Employees] remain because they need to do so. Finally, normative commitment reflects a feeling of obligation to continue employment. Employees with a high level of normative commitment feel that they ought to remain with the organization (p.67).

The employment contract includes obligations of two parties as well as compensation figures and conditions for a long-term work environment (Rousseau, 1989) whereby economic terms primarily structure the commitment. The loyalty of 
the employees and the extra effort employees willing to put, which also tap upon organizational commitment, enhance the overall effectiveness of the organization and the individuals (Bateman \& Strasser, 1984) where the normative forces keep the individual connected with the organization. Considering the affective commitment dimension, individuals that are experiencing particular psychological states of trust, confidence and reliance in regards to their peers and management team, are associated with the organization more through their emotions and affect based judgments. Therefore, the current model will explore and shed more light into the determinants of affective organizational commitment which appears to be the most relevant commitment factor in a trust context.

Mawhinney (2011) discussed job satisfaction and its theoretical background in industrial organization research and its empirical standpoint in organizational behavior. The subjective constructs attempting to capture attitudinal and behavioral phenomena appear to weigh heavy in organizational research. Contemporary organizations emphasize employees' psychological welfare as well as physical working conditions. Satisfaction as an attitudinal construct can be argued to have positive performance implications, thereby contributing to overall work environment. As such, in the current study, secondarily we aim to address the influence of -if any- interpersonal trust on the individual's job satisfaction which is conceptualized as a subjective construct. It can be argued that individuals while cognitively experiencing trust in their peers and supervisors, they may well be dissatisfied with the salary and/or working conditions. On the other hand, interpersonal trust as a source of positive expectations can deteriorate the experienced feelings of anxiety and doubt (Yang, 2005). In this vein, interpersonal trust can be argued to be closely associated with different satisfaction perceptions (Ellis \& Shockley-Zalabak, 2001) however; it needs further exploration including a multi-foci analysis with contextual factors.

Third focus of the current study is the connection between interpersonal trust and turnover intention of employees. Discontinuance of work is associated with a variety of costs from recruiting and training of new employees, to stalled customer relationships, decreased employee satisfaction and productivity (Davis et al., 2000). In the current research, turnover is also investigated which still holds as an important employee problem with today's organizations (Mayfield \&Mayfield, 2008). In order to address the turnover problem, the attitudinal precedent of actual turnover level which is turnover intention is captured in the model. This study's departure point is to pose interpersonal trust variables as determinants of attitudinal and behavioral outcomes including turnover intention.

The relationships between variables of interest in organizational behavior are most of the time a function of the context. It is important to address factors that influence the relationship between the individual and the organization, the employee and his/her professional social network in the organization. Moreover, the physical environment of the workplace, the job duties, job responsibilities, role 
ambiguity and job autonomy are among those that can be counted as contextual factors. One can argue that these factors could be highly intertwined with the interdependency of the employees in the organization with regards to solving problems and making decisions. Considering the different job positions and objectives of the organization, controlling for role ambiguity and job autonomy can help capture the contextual conditions. Therefore, the analyses of the trust relationships can be taken into account more robustly. In current theoretical model, investigation of the trust situations by including role ambiguity and job autonomy is considered as an important step exploring the context dimension.

Current study utilizes the trust in peers and trust in senior management constructs to capture the psychological state of the individuals towards particular group of people in the same organization. In addition, propensity to trust construct is included in order to address the dispositional dimension of trust which is grounded in the psychology research (Deutsch, 1958; Rotter, 1967, 1971). In personality research, propensity to trust has been traditionally hypothesized to affect interpersonal trust that is vested in specific objects. Therefore, in the current model, propensity to trust is hypothesized to directly determine the actual level of trust that the individual cognitively experiences. The theoretical model includes three behavioral and workplace outcome variables: Affective commitment, turnover intention, and job satisfaction (See Figure 1). To what extent these job outcome variables could be explained directly by trust variables are of central to the current study.

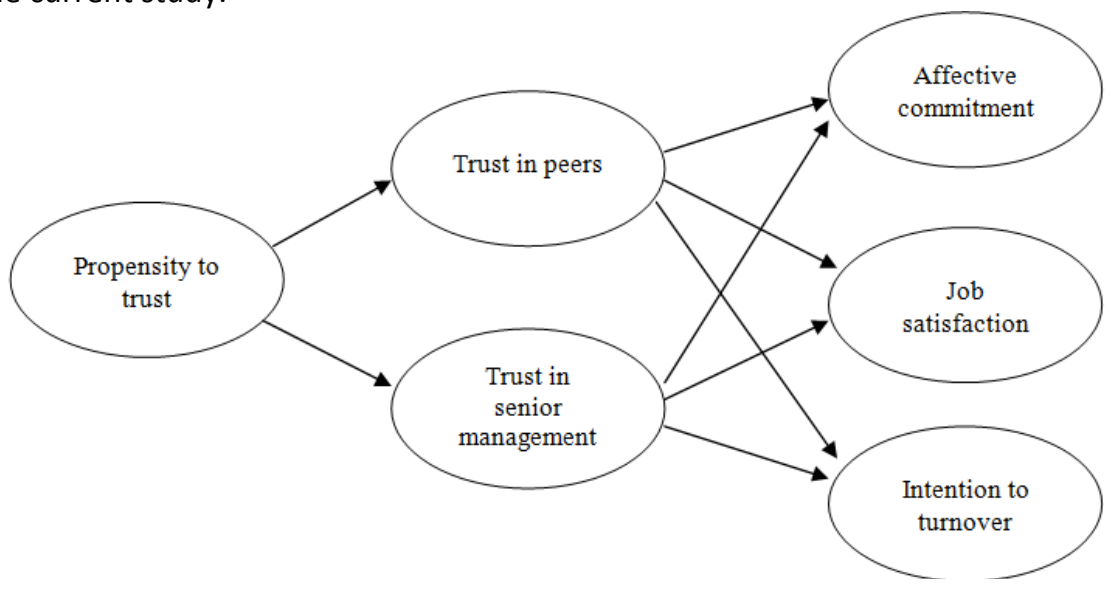

\section{Figure 1. Theoretical Model of Interpersonal Trust and Related Outcomes}

Trust in the organization including linkages between trust constructs and behavioral/institutional variables etc. is well established in the literature. However, empirical research in interpersonal trust that covered the simultaneous inclusion of trust variables directed towards multiple objects is limited. An individual might interact with and experience a psychological state of interpersonal trust towards a 
diverse set of organizational members; including subordinates, peers, supervisors and senior management. This study would fill this aforementioned gap by asking the question of "What are the specific effects of interpersonal trust in peers and senior management on organizational behavior?" Considering the contextual factors such as organizational and job characteristics, the simultaneous inclusion of two trust variables brings rigor to the theoretical model in the sense that the trust variables capture the majority of the organizational members as objects of trust. Therefore, distinctive impacts of interpersonal trust on each of the outcome variables can be observed.

Organizational and job characteristics are included to reveal the emphasis of workplace environment and work design. As such, current research addressed the impact of type of the organization (non-profit vs. for-profit), number of people working in the organization as an indicator of the size of the organization, job autonomy, conflict and role ambiguity (Rizzo, House \& Lirtzman, 1970) as various aspects of work design. By separating the influences of these control variables in the analytical model, pure impact of interpersonal trust on global workplace outcomes is investigated.

\subsection{Interpersonal Trust in Turkish Cultural Context}

Current research studied interpersonal trust and its relationship with behavioral constructs in Turkey where the national culture appears to be more of a collectivistic one according to a major anthropological and social psychological study (Hofstede, 2001). Hofstede's seminal study of IBM paved the ground for establishing a framework highlighting the cultural differences which is still receiving academic interest (e.g. Taras, Kirkman \&Steel, 2010; Huettinger, 2008). In this cultural typology, Hofstede coined a number of cultural dimensions and measured scores for each of these dimensions. These include individualism-collectivism, masculinity-femininity, power distance, uncertainty avoidance and long-term orientation. Among these cultural dimensions, we argue that Turkey stands out in two of the cultural dimensions: Collectivism and power distance. In order to further justify the selection of country within the context of cultural values, current research will utilize discussions of these cultural constructs allowing for a sound discussion and speculation on particular results.

Turkey is regarded to be high on collectivism (score of individualism is very low of 37 compared to US score of 91) and high on power distance dimension. Hofstede (2001) noted that "collectivism stands for a society in which people from birth onwards are integrated into strong, cohesive in-groups, which throughout people's lifetime continue to protect them in exchange for unquestioning loyalty." (p. 225,). In this regard, the citizens of Turkey can be argued to value the interests and preferences of the (social) group and family that the individual is part of. It then appears to be valid framework to argue that the peer environment as well as the seniority of contacts is given loyalty without much of a received grace. Considering 
that people of Turkey takes this cognition towards in-groups for granted, the psychological state of experiencing interpersonal trust might be argued to have strong presence in explaining a number of behavioral phenomenon. On the other hand, power distance prevails as an important indicator of culture in regards to power distribution in social life and organizations. Power distance refers to unequal distribution of power and its perception across organizational members (Hofstede, 2001). The relationship between organizational members and different levels of authority is one factor determines the behavior. Turkish culture scoring high on this particular dimension implies that there might be different perceptions of individuals towards people of the same organization but at different organizational hierarchy. Considering that different foci of the interpersonal trust in the current model is the core of theoretical model, this research explores whether the differences between trust levels on the peers and management could be speculated by this particular cultural dimension. Therefore, at this junction, current research benefits from the underlying implications of high collectivism and high power distance in Turkey, explaining the interrelations of organizational behavior and linking trust into these particular cultural dimensions.

\section{Theoretical Framework and Hypothesis}

The current research benefited from the discussions of trust as a psychological state that is determined throughout the childhood period of an individual. Therefore, it is considered to be a crucial element of the personality that is consistent across situations and has a stable nature. Deutsch (1958) and Rotter $(1967,1971)$ contributed to the understanding of the dispositional trust that could also be linked to a general faith in others (Rosenberg, 1956). According to the literature in this research stream, the trait-like characteristics in a certain individual may explain some of the trust phenomenon. Therefore, the assumption employed in the current study is that the trust in a certain object (i.e., colleagues, friends, and organization) is partly determined by the dispositional trust or propensity to trust that has evolved and developed over time mostly in the childhood period of the individual.

Rotter (1967) explicated that interpersonal trust is a form of expectancy of future behavior, verbal or written promise of another party. Because the trustor assumes the possibility of these future behaviors to be valid, vulnerability becomes a critical aspect of interpersonal trust. According to Erikson (1953), trust is a necessary ingredient in a healthy personality that functions as glue that facilitates interaction. Having lowered the transaction costs in an organization, professionals can manage their interdependencies effectively giving rise to the enhanced individual and organizational outcomes. Mayer et al. (1995) has developed an integrative model of trust within organizational context further detailing the concept of propensity to trust. In Mayer et al. (1995)'s model, propensity to trust is defined as "general willingness to trust others" (p. 715) which defines the extent which trustor will have confidence on the other party prior to the contact or any other information. 
Therefore; trust in peers and senior/top management would very well be a function of the dispositional aspects of trust in one's personality. Based on the discussions above and from a normative point of view, following hypotheses are formulated:

$H_{1}$ : Propensity to trust enhances the psychological state of trust in peers.

$\mathrm{H}_{2}$ : Propensity to trust enhances the psychological state of trust in senior management.

The trust literature in management research (Mayer et al., 1995) draws upon the discussions of Luhmann (1988) and Barber (1983). These thinkers addressed trust concept from a more general point of view and their writings posed trust in a social context. Luhmann's (1979) discussions of trust consider trust as a tool for dealing with the uncertainty and complexity that surrounds people in everyday life. He argued that it is basically a heuristic that allows individuals to sustain life, and he affirms the necessity of trust in the social order. Barber's writings explicate the link between the expectations about the trusted party and the trustor. The nature of the relationship between culture and trust, the extent to which a trusted party is technically competent and the expectations of trustor are among the issues on which Barber (1983) predicated his arguments. Putnam (1993) also argued that with the existence of trust, transaction costs are lowered and professionals function efficiently in workplaces. At this junction, affective commitment as an emotional bond that stimulates the employee to exert extra effort in the workplace towards organizational goals (Meyer \&Allen, 1997) is argued to entail an extensive trust relationship. Due to the satisfaction of expectations as well as confirmation of the competencies of the respective party (i.e., peers and senior management) the individual would submit to higher social order, and experience a strengthened connection with the entity as a whole. The quality of the relationship between the professionals in organizations indicates that the individuals can better identify themselves with the organization thereby giving rise to the organizational commitment. Noting the multidimensional nature of the organizational commitment, the affective commitment only is investigated in the present study. Confirming to the extant literature, positive association between trust variables and affective commitment is hypothesized (Ferres et al., 2004):

$H_{3}$ : Trust in peers determines and is positively associated with the affective commitment.

$H_{4}$ : Trust in senior management determines and is positively associated with the affective commitment.

The relationship between turnover intention and trust in coworkers, and senior management can be argued to be to some extent intuitive. The level of vulnerability upon a trust relationship, which is perceived by the employee, will be directly associated with the intention to leave the organization. The vulnerability perspective embedded in the psychology of a trust state imposes that the individual is willing to incur or experience the risk of possible outcomes. If an individual does 
not perceive a risky relationship, from a deductive sense, the individual is experiencing less vulnerability thereby higher level of interpersonal trust. In other words, employee would feel a more stable job position in the organization therefore the lesser the vulnerability is perceived. Thereby, it will strengthen the organizational commitment and lower the intention to quit. At this junction, benefiting from a particular approach towards trust is also helpful. Trust is particularly related to "calculation of likelihood of future cooperation" (Smith, 2010, p. 46, emphasis added) which enables professionals to operate efficiently in an environment minimizing the transactions costs (Putnam, 1993). In line with the findings of Shore, Tetrick, Lynch and Barksdale (2006) and Davis et al. (2000), we argue that trust, as an element of social exchange, can enhance and ensure the employment of the individual deteriorating turnover intention:

$H_{5}$ : Trust in peers undermines turnover intention.

$H_{6}$ : Trust in senior management undermines turnover intention.

Trust foci matter in explaining the variance in job satisfaction considering the findings of Yang (2005). Each trust variable might possess unique predictive power of the employee's satisfaction with the job. In line with the extant empirical support on the trust and job satisfaction relationship (Rich, 1997; Tan \&Tan, 2000), we take a neutral stance and formulate that:

$H_{7}$ : Trust in peers is associated with job satisfaction

$H_{8}$ : Trust in senior management is associated with job satisfaction

\section{Methodology}

Statistical method employed in this study is Structural Equation Modeling (SEM) analysis using partial least square (PLS) (Wold, 1985; Fornell \& Larcker, 1981). The strength of this method is that violation of normality assumption will not distort PLS estimations. The structural associations between variables of interest can be constructed using either confirmatory or exploratory methods in PLS studies (Kock;2010, 2012). The conceptual model shown in Figure 1 involves a number of latent variables. Latent variables are abstractions and their measurement requires specific procedures that are different than the measurement of the manifest variables, which are easily observable and therefore measurable directly from solid indicators (Schumacker \&Lomax, 2004). In order to address and capture the meaning intended by a latent variable, a number of indicators are measured and then certain factor analytic procedures is followed. This procedure generates scores for a latent variable derived from the interrelationships of items that measure this particular latent variable. In this study, all latent variables are reflective (Chin, 1998). Each item in the survey served as an indicator for the respective reflective latent variable implies that the indicators tap on the same phenomenon in a different way. Indicators are used as items capturing the variance in the respective variable by tapping on the abstraction from different ways. Therefore there is abundance of indicators which may be dropped in case of weak psychometric 
properties. In the analytical model propensity to trust, trust in peers and in senior management, affective commitment, job satisfaction and turnover intention are formed as latent variables.

Survey method was employed in the study. The survey scales for each of variables were adopted from prior research. All of the survey scales proved to be reliable and valid measurement tools satisfying multiple validity checks including convergent and discriminant validity. Role ambiguity, job autonomy, income, educational attainment, size of the organization and demographic variables were taken into consideration as control variables to capture the relevant influence of these contextual factors. All of the survey scales are likert scales ranging from 1 to 5 (i.e., size of the organization; 1 for "1-50", 5 for "1001 and more").

\subsection{Data Collection and Sample}

Respondents of the survey are full-time and part-time professionals working or have worked in Turkey. Data collected through both online and hardcopy surveys. Data collection was conducted using convenience sampling. Respond rate is not applicable due to the reach of survey through website and therefore sample is not a random sampling. After cleaning data, sample size was recorded as $134(\mathrm{~N})$. The average age in the sample is 32.9, twenty five percent of the respondents are female and sixty percent of the sample is married. The average experience was recorded as 9.8 year. The average tenure was 5.9 year. Those who are working with a non-profit organization constitute forty three percent of the sample. The educational statistics are as follows: High School graduates five percent, Some College three percent, Bachelor's thirty three percent, Graduate Certificate four percent, Master's Degree twenty nine percent, beyond Master's twenty five percent. Correlations matrix of latent variables is given below in Table 1.

Table 1. Means, Standard Deviations and Correlations of Variables

\begin{tabular}{lccccccc}
\hline & Mean & SD & 1 & 2 & 3 & 4 & 5 \\
\hline 1. Propensity to Trust & 2.80 & 0.57 & & & & & \\
2. Trust in Peers & 2.96 & 0.82 & $0.26^{* *}$ & & & \\
3. Trust in Senior Management & 2.93 & 0.87 & $0.26^{* *}$ & $0.34^{* *}$ & & \\
4. Affective Commitment & 3.54 & 0.81 & $0.20^{\mathrm{a}}$ & $0.28^{* *}$ & $0.28^{* *}$ & \\
5. Job Satisfaction & 3.59 & 0.59 & $0.27^{*}$ & $0.18^{*}$ & $0.30^{* *}$ & $0.51^{* *}$ & \\
6. Turnover Intention & 2.76 & 0.75 & $-0.15^{\mathrm{a}}$ & $-0.18^{*}$ & $-0.24^{* *}-0.59^{* *}-0.51^{* *}$ \\
\hline${ }^{\mathrm{a}} \mathrm{p}<0.10,{ }^{*} \mathrm{p}<0.05,{ }^{* *} \mathrm{p}<0.01$. & & & & & & &
\end{tabular}

\subsection{Analysis}

WarpPLS 3.0 software is used to analyze sample data. Jackknifing resampling method for the current study is selected as opposed to bootstrapping and blindfolding because more stable beta coefficients were generated. Jackknifing, in presence of outliers in small samples as well as with non-random samples, is powerful in estimating stable coefficients (Kock, 2012). The current study employed 
confirmatory factor analysis. In Table 2 below, the indicators for each of the latent variable, their corresponding loading scores from a pattern matrix (i.e., rotated factor scores) and reliability coefficients are given. Those indicators with loadings substantially less than adequate level (i.e., less than 0.5) are excluded from the statistical analyses and therefore not shown. All of the loadings with one exception, which is dropped from analysis, are higher than 0.5 showing convergent validity (Hair, Black, Babin \& Anderson, 2009). The confirmatory factor analysis generated reliable latent variables. Reliabilities of propensity to trust, trust in peers and trust in senior management are recorded as $0.76,0.75$ and 0.78 and recorded as higher than the required 0.7 level (Hair et al., 1992; Nunnally \& Bernstein, 1994). Reliability scores of the workplace outcome variables are slightly higher than other latent variables implying the supposed relative strength of the measurement scales of the constructs.

\section{Table 2. Indicator Loadings from Pattern Matrix}

\begin{tabular}{|c|c|c|c|}
\hline Latent Variable and Source & Indicator code & Loading score & Composite reliability \\
\hline \multirow{6}{*}{$\begin{array}{l}\text { Propensity to trust } \\
\text { (Mayer \& Davis, 1999) }\end{array}$} & $\mathrm{D} 2$ & 0.679 & \multirow{6}{*}{0.759} \\
\hline & D3 & 0.489 & \\
\hline & D5 & 0.654 & \\
\hline & D6 & 0.557 & \\
\hline & D7 & 0.512 & \\
\hline & D8 & 0.620 & \\
\hline \multirow{3}{*}{$\begin{array}{l}\text { Trust in peers } \\
\text { (Mayer \& Davis, 1999) }\end{array}$} & T1P & 0.748 & \multirow{3}{*}{0.749} \\
\hline & $\mathrm{T} 2 \mathrm{P}$ & 0.686 & \\
\hline & $\mathrm{T} 4 \mathrm{P}$ & 0.683 & \\
\hline \multirow{3}{*}{$\begin{array}{l}\text { Trust in senior management } \\
\text { (Mayer \& Davis, 1999) }\end{array}$} & T1M & 0.663 & \multirow{3}{*}{0.777} \\
\hline & $\mathrm{T} 2 \mathrm{M}$ & 0.778 & \\
\hline & $\mathrm{T} 4 \mathrm{M}$ & 0.755 & \\
\hline \multirow{6}{*}{$\begin{array}{l}\text { Affective commitment } \\
\text { (Allen \& Meyer, 1990) }\end{array}$} & AC1 & 0.664 & \multirow{6}{*}{0.878} \\
\hline & $\mathrm{AC3}$ & 0.567 & \\
\hline & AC5 & 0.755 & \\
\hline & AC6 & 0.844 & \\
\hline & $\mathrm{AC7}$ & 0.735 & \\
\hline & $\mathrm{AC} 8$ & 0.842 & \\
\hline \multirow{6}{*}{$\begin{array}{l}\text { Job satisfaction } \\
\text { (Macdonald \& Maclntyre, 1997) }\end{array}$} & JS1 & 0.644 & \multirow{6}{*}{0.781} \\
\hline & JS2 & 0.572 & \\
\hline & JS4 & 0.647 & \\
\hline & JS5 & 0.653 & \\
\hline & JS8 & 0.644 & \\
\hline & JS9 & 0.499 & \\
\hline \multirow{6}{*}{$\begin{array}{l}\text { Turnover intention } \\
\text { (Mayfield \& Mayfield, 2008) }\end{array}$} & ITT1 & 0.580 & \multirow{6}{*}{0.832} \\
\hline & ITT3 & 0.736 & \\
\hline & ITT4 & 0.707 & \\
\hline & ITT5 & 0.758 & \\
\hline & ITT6 & 0.703 & \\
\hline & ITT7 & 0.537 & \\
\hline
\end{tabular}


Full collinearity tests were carried out and VIF scores are provided in Table 3 . The VIFs vary from low of 1.314 (Trust in peers) to 2.171 (Affective commitment) showing that multi collinearity among these constructs does not pose any substantial risk. The full collinearity check based on the variance inflation factors (VIF) serves for detecting possible collinearity. Traditional VIF level is 5 whereas from a less strict perspective VIFs should be lower than 10 (Hair et al., 2009). The highest VIF (2.171) was recorded for affective commitment variable. Most of the VIFs scores are even lower than the threshold of 3.3 (Kock, 2012).

Table 3. Latent Variable Coefficients

\begin{tabular}{lccc}
\hline & R-squared & Composite reliability & Full collinearity VIFs \\
\hline Propensity to Trust &. & 0.759 & 1.426 \\
Trust in Peers & 0.07 & 0.749 & 1.314 \\
Trust in Senior Management & 0.07 & 0.777 & 1.450 \\
Affective Commitment & 0.28 & 0.878 & 2.171 \\
Job Satisfaction & 0.28 & 0.781 & 2.031 \\
Turnover Intention & 0.32 & 0.832 & 2.064 \\
\hline
\end{tabular}

Using the average variance extracted (AVE) coefficients; discriminant validity of the latent variables can be shown (Chin, Marcolin, \& Newsted, 2003). Such criterion has been prevalently used in management and organization research (Ringle, Sarstedt \&Straub, 2012). In the Table 4 below, the square roots of AVEs are shown on the diagonal. Square roots of average variance extracted are expected to be lower than the latent variable correlations. These coefficients are all larger than the respective correlations. Therefore, survey questions as indicators measuring particular latent variables did not have substantial overlapping (i.e., indicators of different latent variables are measuring same phenomenon).

Table 4. Latent Variable Correlations and Square Roots of AVEs

\begin{tabular}{lcccccc}
\hline & 1 & 2 & 3 & 4 & 5 & 6 \\
\hline 1. Propensity to Trust & $(0.589)$ & & & & & \\
2. Trust in Peers & 0.266 & $(0.706)$ & & & & \\
3. Trust in Senior Management & 0.261 & 0.340 & $(0.734)$ & & & \\
4. Affective Commitment & 0.209 & 0.280 & 0.285 & $(0.741)$ & & \\
5. Job Satisfaction & 0.271 & 0.184 & 0.305 & 0.515 & $(0.612)$ & \\
6. Turnover Intention & -0.154 & -0.180 & -0.244 & -0.599 & -0.515 & $(0.675)$ \\
\hline
\end{tabular}

\section{Results}

Estimated path coefficients and the R-squared coefficients are provided on the Figure 2. In the model, the constructs are created through the responses of the individuals therefore the level of analysis is at the individual level. The control variables included in the model for workplace outcomes are role ambiguity, job autonomy, tenure (in years), gender, number of employees in the organization (size), profit seeking/non-profit organization, marital status, age and interaction terms for interpersonal trust with frequency of contact respective of the trust foci. 


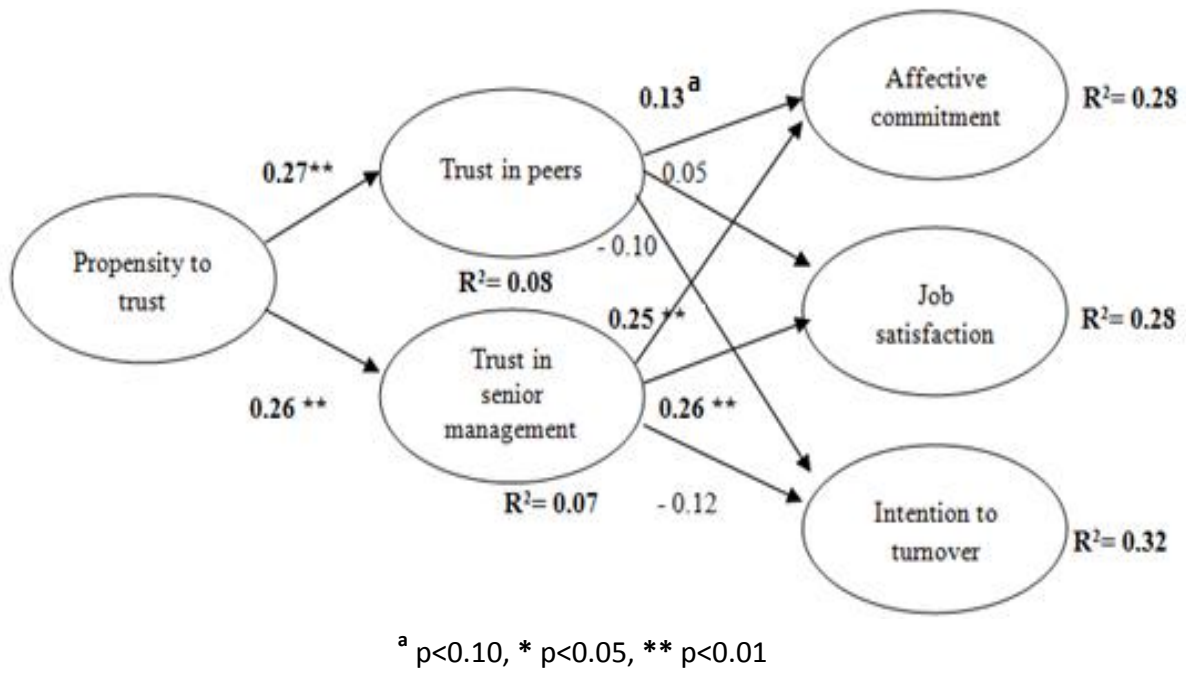

Figure 2. Estimated Standardized Coefficients of the Theoretical Model

Hypothesis 1 and 2are supported by the empirical findings. Between propensity to trust and trust in peers/senior management, path coefficients are estimated to be significant and positive. Path coefficients are $(\beta=0.27, p<0.01)$ and $(\beta=0.26$, $p<0.01$ ) respectively. Empirical support was found for the hypothesis 3 and 4 as well. The links between trust in peers and affective commitment proved to be positive however marginally significant $(\beta=0.13, p<0.10)$. Similarly, the links between trust in senior management and affective commitment were found to be substantial $(\beta=0.25, p<0.01)$.

The interpersonal trust in peers and senior management are hypothesized to predict the turnover intention of employees however the estimated coefficients are not significant to accept the initial departure point. Thus, hypotheses 5 and 6 did not receive any empirical support.

Trust in peers is not significantly associated with individual job satisfaction. Hypothesis 7 does not receive any support from the empirical results. However for hypothesis 8 , empirical support is recorded. Trust in senior management predicted the level of individual job satisfaction $(\beta=0.26, p<0.01)$.

Estimated coefficients of control variables were provided in the Table 5 below. Role ambiguity was found to significantly increase turnover intention, and job satisfaction, interestingly. The employees with less precise job roles and ambiguous job duties were experienced higher satisfaction. Higher the job autonomy is, lower turnover intention of employees is. Having limited work experience at the same organization (measured as tenure) is related with low level of affective commitment and individual job satisfaction. Women professionals are found to have higher job satisfaction. In larger organizations, the degree of willingness to be vulnerable is 
associated with commitment of the individual. Experiencing higher interpersonal trust translates into higher affective commitment. In addition, employees appeared to be committed more to larger organizations than smaller organizations. Those who are not married are experiencing higher turnover intention. In commercial organizations as opposed to non-profit organizations, workers experienced lower affective commitment. Those who work with a non-profit organization and female professionals on average perceived higher job satisfaction.

The interaction effects in the model present important findings as well. The frequency of contact with peers and actual trust in peers explained job satisfaction substantially. The employees feel more satisfied and happy as the employee and peers interact more often. By the same token, employees' interaction with senior management found to be associated with behavioral and attitudinal outcomes. The positive association was recorded for affective commitment and job satisfaction. Higher interaction and contact also deteriorate the turnover intention. Such findings bring further evidence for the social exchange perspective which is built upon the reciprocity of exchange among organizational members (Cropanzano \& Mitchell, 2005).

\section{Table 5. The Estimated Standardized Coefficients of the Control Variables}

\begin{tabular}{lccc}
\hline & \multicolumn{3}{c}{ Dependent Variables } \\
\cline { 2 - 4 } & $\begin{array}{c}\text { Affective } \\
\text { Commitment }\end{array}$ & $\begin{array}{c}\text { Job } \\
\text { Satisfaction }\end{array}$ & $\begin{array}{c}\text { Turnover } \\
\text { Intention }\end{array}$ \\
\cline { 2 - 4 } Role Ambiguity & 0.03 & $0.26^{*}$ & $0.05^{\mathrm{a}}$ \\
Job Autonomy & 0.14 & 0.11 & $-0.18^{*}$ \\
Tenure & $0.17^{\mathrm{a}}$ & $0.16^{\mathrm{a}}$ & -0.06 \\
Female & -0.02 & $0.16^{*}$ & 0.03 \\
Size of the organization & $0.14^{*}$ & -0.15 & -0.11 \\
Married (1=Yes) & 0.00 & -0.02 & $-0.19^{*}$ \\
Non-Profit organization (1=Yes) & $0.26^{* *}$ & $0.16^{*}$ & -0.08 \\
Age & 0.06 & -0.02 & -0.10 \\
Frequency of contact with Peers * Trust in Peers & 0.11 & $0.23^{\mathrm{a}}$ & -0.16 \\
Frequency of contact with Senior Mgt * Trust in & $0.18^{*}$ & $0.15^{*}$ & $-0.17^{*}$ \\
Senior Mgt & & &
\end{tabular}

${ }^{a} p<0.10,{ }^{*} p<0.05,{ }^{* *} p<0.01$

Effect sizes are measures of practical sense of meaning related to an estimated coefficient (Cohen, 1988; Kock, 2012). All of the effect sizes calculated ${ }^{1}$ fall between small and medium size in this research supporting the notion that statistical findings are remarkable and practically significant as well.

\section{Discussion and Conclusion}

In the current study, interpersonal trust as a psychological state was investigated and found to be associated with several workplace outcomes. The frontiers of

${ }^{1}$ Available upon request from the author. 
knowledge in organizational behavior are expanded by the empirical evidence offered in this research supporting the normative point of view of interpersonal trust (e.g., Erikson, 1953). The results presented offer unique implementations as well as further confirmation of the prior literature (e.g., Dirks \& Ferrin, 2002). Current research investigating the function of interpersonal trust within organizational context concluded that the trust is a remarkable catalyst enhancing interpersonal relationships. Those who experience particular trust to their peers and senior managers will be more connected to the organization in terms of commitment to organizational goals and aims (Ferres et al., 2004; Kaneshiro, 2008; de Ruyter et al., 2001; Yang, 2005). Therefore, interpersonal trust is supporting the "at home" feeling during work as well as the perception of the self as "part of the family". Considering the collectivistic nature of Turkish people, the value of groups (i.e., peers and the management) that partially defines the individual, appears to have implications related to particular organizational behavior. Thus, the overall extra effort to be put on the job by the employees is facilitated through interpersonal trust. The current research has also found that trust in senior management improves the individual job satisfaction concurring with prior evidence (Rich, 1997). However, trust in peers does not significantly associate with employee job satisfaction. For the employees perceiving less vulnerability with respect to their superiors, it can be said that they are spending less time and effort to protect their posts therefore focusing on their immediate work. The employees experiencing anxiety about their relationship to senior managers are diverting their psychological energy towards reconciling their interpersonal connections which can lead to inefficiency. One can also connect such conclusion to power distance between people of different levels of authority in the organizations in Turkey (Hofstede, 2001). The social distance between the employee and senior management can superimpose a taken for granted trust relationship and thereby enhancing the perception of the individual in regards to employment conditions. As such positive perceptions of wage, promotion, relationship with supervisor, feeling safe at work are leveraged and higher individual pleasure and happiness with the job is observed (Macdonald \& Maclntyre 1997). Similarly, trust vested in higher authority is more explicatory of the workplace attitude in regards to affective commitment and job satisfaction.

In regards to the turnover intention, interpersonal trust does not play any role in predicting which speculatively support the argument that quitting an organization is primarily related to the terms in an economic exchange rather than social exchange. Even though literature suggests that employee behavior in relation to absences and tardiness, -consequently leaving the organization- is more connected with social exchange (Shore et al., 2006) our empirical results do not confirm. Interpersonal trust as a social exchange element does not appear to be correlated with some work behavior indicating the fact that such relationship is more of a product of economic exchange. In economic exchange, explicit and specified exchange of 
resources is of central therefore decisions relevant to leaving the organization can be associated with the quantified terms of the contract.

Social exchange is essentially based on the norm of reciprocity therefore as the individuals engage in quality give-and-take behaviors, over time the individuals develop higher trust towards peers as well as commitment to each other (Blau, 1964; Cropanzano \& Mitchell, 2005). Higher interaction frequency of the peers will enrich the realized social exchange. Strong bonds among peers translate into the identification of employees with the organization and individuals tend to have higher sense of belonging and involvement. By the same token, believing in the fact that the management of the organization "will not let you down" (i.e., no matter what happens, the employment of the individual is safe) can further the organizational commitment by lowering the risks associated with continuance of the employment (Rousseau, 1989).

\subsection{Practical Implications}

The associations between propensity to trust and trust vested in particular subjects are further empirically validated. Such findings raise the importance of personality tests especially in hiring practices. The hiring practices are crucial steps towards effective human resources in organizations. Because such dispositional tendency in employees can be linked to higher overall effectives of certain organizational behavior, hiring committees may involve specialized tests to reveal and understand the applicant's personality. Though trusting in an applicant does not necessitate a higher intention to hire from an employer perspective (Yang et al., 2011), the higher propensity to trust of the applicant can be considered as a plus compared to lower propensity applicants among other decision making criterion. Therefore, the hiring practices which can be considered as the gate for building effective human resources in organizations can be enhanced by examining applicants' personality with respect to their propensity to trust. Because such dispositional tendency in employees can be linked to higher overall effectives, the hiring committee in an organization shall involve specialized tests to actually reveal and understand the applicant's character thoroughly.

Finally, training of employees and managers are recommended with respect to the importance of interpersonal trust in the organization. The value and outcomes of having healthy relationships involving trust in the organization can be precious. First, the organizational members must be aware of the fact that at all levels in the organization the vulnerability among individuals due to the interdependence prevails. Second, the trust in organizational members is indeed the social glue that can facilitate and increase efficient engagement among personnel. Third, considering the trust as a product of social exchange and interactions between employees, the professional relationships can be enhanced by formally or informally organizing social programs, engagements and get-togethers. Training and 
building quality interpersonal relationships in the organizations involving the trust dimension should be a priority in managers' agendas.

\section{Limitations and Future Research}

Among the workplace outcome variables, prior research discussed the causal relations. Correlations among affective commitment, job satisfaction and turnover intention could very well be due to the causality reasons that are not specified in the current research model. Using path analysis based on meta-analytic study Tett and Meyer (1993) concluded that "satisfaction and commitment each contribute uniquely to turnover intention" (p.285). In the current research, such relationships were simply bypassed which might have changed the analysis results if included. Furthering the current model with aforementioned associations of satisfaction, commitment and turnover intention, can cast more light into the underlying behavioral phenomenon.

Second, propensity to trust is defined in this study as a construct that partially determine the interpersonal trust in addition to the characteristics of trustee which is not covered here. In the current model, propensity to trust from personality perspective is not argued to have an independent effect on behavioral outcomes directly but rather it is conceived as an antecedent of actual trust. Future research can shed more light into the possible direct influence of the personality and characteristics of trustor on the global work attitudes and behavior.

\section{Acknowledgement}

I would like to thank the Editor and two anonymous reviewers for their valuable feedback and comments that certainly improved the quality of the manuscript. I am also grateful to the participants of the Research Seminar Series at Gediz University for their constructive feedback, especially Dr. Vener Garayev and Dr. Tuğba Kocabiyik for their comments on the paper. All remaining errors are mine.

\section{References}

Allen, N. J. and Meyer, J. P. (1990), "The measurement and antecedents of affective, continuance and normative commitment to the organization", Journal of Occupational Psychology, 63(1), 1-18. http://dx.doi.org/10.1111/j.2044-8325.1990.tb00506.x

Barber, B. (1983), "The logic and limits of trust, New Brunswick", NJ: Rutgers Univ. Press

Bateman, T. and Strasser, S. (1984), "A longitudinal analysis of the antecedents of organizational commitment", Academy of Management Journal", 27(1), 95-112. http://dx.doi.org/10.2307/255959

Blau, P. M. (1964), "Exchange and power in social life", New York: John Wiley.

Chin, W. W. (1998), "Commentary: Issues and opinion on structural equation modeling", MIS Quarterly, 22(1), vii-xvi.

Chin, W.W., Marcolin, B.L., and Newsted, P.R. (2003), "A partial least squares latent variable modeling approach for measuring interaction effects: Results from a Monte Carlo simulation 
study and an electronic-mail emotion/adoption study", Information Systems Research, 14(2), 189-218. http://dx.doi.org/10.1287/isre.14.2.189.16018

Clampitt, P., Williams, M.L., \& Korenak, A. (2000). "Managing organizational uncertainty: Conceptualization and measurement". Paper presented at the International Communication Association, Acapulco. Retrieved from: http://imetacomm.com/wpcontent/themes/Structure\%20Premium\%20White/organic_structure_white/downloads/Met acomm_Conceptualizations.pdf

Cohen, J. (1988), "Statistical power analysis for the behavioral sciences", Hillsdale, NJ: Lawrence Erlbaum.

Cropanzano, R.\& Mitchell, M.S. (2005),"Social exchange theory: An interdisciplinary review", Journal of Management, 31(6), 874-900.http://dx.doi.org/10.1177/0149206305279602

Dasgupta, P. (2000). "Economic progress and the ideal of social capital". In P. Dasgupta, \& I. Serageldin. (Ed). Social Capital: A Multifaceted Perspective. The World Bank.

Davis, J. H., Schoorman, F. D., Mayer, R. C. and Tan, H. H. (2000), "Trusted general manager and business unit performance: Empirical evidence of a competitive advantage", Strategic Management Journal, 21(5), 563-576. http://dx.doi.org/10.1002/(SICl)10970266(200005)21:5<563::AID-SMJ99>3.0.CO;2-0

de Ruyter, K., Moorman, L. and Lemmink, J. (2001), "Antecedents of commitment and trust in customer-supplier relationships in high technology markets", Industrial Marketing Management. 30(3), 271-286. http://dx.doi.org/10.1016/S0019-8501(99)00091-7

Deutsch, M. (1958), "Trust and suspicion", Journal of Conflict Resolution, 2(4), 265-279. http://dx.doi.org/10.1177/002200275800200401

Dirks, K. T. and Ferrin, D. L. (2002), "Trust in leadership: Meta-analytic findings and implications for research and practice", Journal of Applied Psychology, 87(4), 611-628. http://dx.doi.org/10.1037/0021-9010.87.4.611

Ellis, K. and Shokley-Zalabak, P. (2001),"Trust in top management and immediate supervisor: The relationship to satisfaction, perceived organizational effectiveness and information $\begin{array}{llll}\text { receiving", } \quad \text { Communication } \quad \text { Quarterly, } & \text { 392-398. }\end{array}$ http://dx.doi.org/10.1080/01463370109385637

Erikson, E. H. (1953), "Growth and cases of the "healthy personality"', In C. Kluckhohn and H. Murray (Eds), Personality in nature, society, and culture (2nd ed.) New York, NY: Knopf.

Ferres, N., Connell, J., and Travaglione, A. (2004), "Co-worker trust as a social catalyst for constructive employee attitudes", Journal of Managerial Psychology, 19(6), 608-622. http://dx.doi.org/10.1108/02683940410551516

Fornell, C., and Larcker, D.F. (1981), "Evaluating structural equation models with unobservable variables and measurement error", Journal of Marketing Research, 18(1), 3950. http://dx.doi.org/10.2307/3151312

Fu, Q. (2004), "Trust, Social Capital and Organizational Effectiveness". Unpublished master's thesis. Retrieved from: http://www.ipg.vt.edu/papers/qhfumajorpaper.pdf

Hair, J. F., Anderson, R. E., Tatham, R. L., and Black, W. C. (1992), “Multivariate data analysis with readings", New York, NY: MacMillan.

Hair, J.F., Black, W.C., Babin, B.J., and Anderson, R.E. (2009),"Multivariate data analysis, Upper Saddle River", NJ: Prentice Hall. 
Hofstede, G. (2001), "Culture's consequences: Comparing values, behaviors, institutions, and organizations across nations (2nd ed.)", Thousand Oaks, California: Sage Publications, Inc.

Huettinger, M. (2008), "Cultural dimensions in business life: Hofstede's indices for Latvia and Lithuania", Baltic Journal of Management, 3(3), 359 - 376. http://dx.doi.org/10.1108/17465260810902414

Kaneshiro, P. (2008), "Analyzing the organizational justice, trust and commitment relationship in a public organization", Ph. D. Thesis, North Central University.

Kock, N. (2010), "Using WarpPLS in e-collaboration studies: An overview of five main analysis steps", International Journal of e-Collaboration, 6(4), 1-11. http://dx.doi.org/10.4018/jec.2010100101

Kock, N. (2012), "WarpPLS 3.0 User Manual", Laredo, Texas: Script Warp Systems.

Luhmann, N. (1979), "Trust and power", New York: John Wiley and Sons.

Luhmann, N. (1988), "Familiarity, confidence, trust: Problems and alternatives", In D. G. Gambetta (Ed.), Trust: 94-107. New York: Basil Blackwell.

Macdonald, S., and MacIntyre, P. (1997), "The generic job satisfaction scale: Scale development and its correlates", Employee Assistance Quarterly, 13(2), 1-16. http://dx.doi.org/10.1300/J022v13n02_01

Mawhinney, T. C. (2011), "Job Satisfaction: I/O Psychology and Organizational Behavior Management Perspectives", Journal of Organizational Behavior Management, 31(4), 288315. http://dx.doi.org/10.1080/01608061.2011.619419

Mayfield, J., and Mayfield, M. (2008), "The creative environment's influence on intent to turnover. A structural equation model and analysis", Management Research News, 31(1), $41-$ 56. http://dx.doi.org/10.1108/01409170810845949

Mayer, R. C. and Davis, J. H. (1999), "The effect of the performance appraisal system on trust for management: A field quasi-experiment", Journal of Applied Psychology, 84(1), 123-136. http://dx.doi.org/10.1037/0021-9010.84.1.123

Mayer, R. C., Davis, J. H., and Schoorman, F. D. (1995), "An integrative model of organizational trust", Academy of Management Review, 20(3), 709-734.

McAllister, D. J. (1995), "Affect- and cognition-based trust as foundations for interpersonal cooperation in organizations", Academy of Management Journal, 38(1), 24-59. http://dx.doi.org/10.2307/256727

Meyer, J. P., \& Allen, N. J. (1991), "A three-component conceptualization of organizational commitment", Human Resource Management Review, 1(1), 61-89. http://dx.doi.org/10.1016/1053-4822(91)90011-Z

Meyer, J. P., and Allen, N. J. (1997), "Commitment in the workplace: Theory, research and applications", Thousand Oaks, CA: Sage.

Misztal, B. (1996), "Trust", Cambridge: Polity Press.

Nunnally, J. C., and Bernstein, I. H. (1994), "Psychometric theory", New York, NY: McGrawHill.

Putnam, R. D. (1993), "Bowling alone", New York: Simon and Schuster Paperbacks.

Rich, G. A. (1997), "The sales manager as a role model: Effects on trust, job satisfaction, and performance of salespeople", Academy of Marketing Science Journal, 25(4), 319-328. http://dx.doi.org/10.1177/0092070397254004 
Ringle, C. M., Sarstedt, M. and Straub, D. W. (2012), "A critical look at the use of PLS-SEM in MIS quarterly", MIS Quarterly, 36(1), iii-xiv.

Rizzo, J. R., House, R. J., and Lirtzman, S. I. (1970), "Role conflict and ambiguity in complex organizations", Administrative Science Quarterly, 15(2), 150-163. http://dx.doi.org/10.2307/2391486

Rosenberg, M. (1956), "Misanthropy and political ideology", American Sociological Review, 21(6), 690-695. http://dx.doi.org/10.2307/2088419

Rotter, J. B. (1967), "A new scale for the measurement of interpersonal trust", Journal of Personality 35(4), 651-665. http://dx.doi.org/10.1111/j.1467-6494.1967.tb01454.x

Rotter, J. B. (1971), "Generalized expectancies for interpersonal trust", American Psychologist, 26(5), 443-452. http://dx.doi.org/10.1037/h0031464

Rousseau, D. M. (1989), "Psychological and implied contracts in organizations", Employee Rights and Responsibilities Journal, 2(2), 121-139. http://dx.doi.org/10.1007/BF01384942

Schumacker, R. E., and Lomax, R. G. (2004), "A beginner's guide to structural equation modeling", Mahwah, N.J.: Lawrence Erlbaum Associates.

Shore, L. M., Tetrick, L. E., Lynch, P. \& Barksdale, K. (2006), "Social and economic exchange: Construct development and validation", Journal of Applied Social Psychology, 36(4), 837-867. http://dx.doi.org/10.1111/i.0021-9029.2006.00046.x

Smith, H., L. (2010), "Interpersonal trust and cooperative behavior in a strategic alliance", (Doctoral dissertation), Retrieved from ProQuest Dissertations and Theses http://pqdtopen.proquest.com/doc/250909605.html?FMT=ABS .

Tan, H. H., and Tan, C. S. F. (2000), "Towards the differentiation of trust in supervisor and trust in organization", Genetic, Social, and General Psychology Monographs, 126(2), 241260.

Taras, V., Kirkman, B. L. and Steel, P. (2010),"Examining the impact of Culture's Consequences: A three-decade, multilevel, meta-analytic review of Hofstede's cultural value dimensions.", Journal of Applied Psychology, 95(3), 405-39. http://dx.doi.org/10.1037/a0018938

Tett, R. P. and Meyer, J. P. (1993), "Job satisfaction, organizational commitment, turnover intention: Path analyses based on meta-analytic findings", Personnel Psychology, 46(2), 259 293. http://dx.doi.org/10.1111/j.1744-6570.1993.tb00874.x

Wold, H. (1985), "Partial Least Squares", In S. Kotz and N. L. Johnson (Eds.), Encyclopedia of Statistical Sciences (Volume 6), New York: Wiley, 581-591.

Yang, J. (2005), "The role of trust in organizations: Do foci and bases matter?" PhD dissertation submitted to the Graduate Faculty of the Louisiana State University and Agricultural and Mechanical College, Retrieved from http://etd.Isu.edu/docs/available/etd04052005-111446/unrestricted/Yang_dis.pdf.

Yang, C., Colarelli, S. M., Han, K. and Page, R. (2011), "Start-up and hiring practices of immigrant entrepreneurs: An empirical study from an evolutionary psychological perspective", International Business Review, 20(6), 636-645. http://dx.doi.org/10.1016/j.ibusrev.2011.02.016 